\title{
Expressão gênica dos REa, REß e PR em tumores mamários de cadelas por meio do q-PCR
}

$[R E \alpha, R E \beta$ and $P R$ gene expression in mammary gland tumors of female dogs by $q-P C R]$

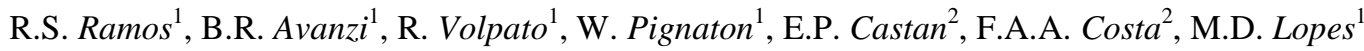 \\ ${ }^{1}$ Faculdade de Medicina Veterinária e Zootecnia - UNESP - Botucatu, SP \\ ${ }^{2}$ Instituto de Biociências - UNESP - Botucatu, SP
}

\begin{abstract}
RESUMO
A expressão de receptores de estrógeno (ER) e progesterona (PR) por meio da técnica de q-PCR foi avaliada em 26 cadelas portadoras de neoplasias mamárias e cinco cadelas sem afecções mamárias (grupo controle). Os resultados mostraram que os três grupos de animais estudados - com tumor maligno ou benigno e controle - expressaram receptores de estrógeno alfa, beta e progesterona. A quantificação relativa mostrou tendência para uma expressão maior de receptores no grupo controle e menor no grupo de animais com neoplasias malignas. Além disso, observou-se expressão maior de ER $\alpha$ em relação ao $\mathrm{ER} \beta$, e as neoplasias malignas de origem mista apresentaram maiores concentrações dos receptores PR, ER $\alpha$ e ER $\beta$ que as neoplasias de origem epitelial.
\end{abstract}

Palavras-chave: cadela, neoplasia mamária, estrógeno, progesterona, receptores

\begin{abstract}
The estrogen and progesterone receptor (ER and $P R)$ expression with the q-PCR technique was evaluated in 26 female dog carrying of mammary tumors and five female dogs without mammary disease (control group). The results showed that the three animal groups evaluated - malignant or benign tumor and control - expressed alpha and beta estrogen and progesterone receptors. The relative quantification showed a tendency for a higher expression of receptors from the control group and smaller in the malignat tumors animal group. Also, there was a major ERa expression regarding to ER $\beta$ and the malignat tumors from mixed origin presented higher concentrations of receptors $P R$, ER $\alpha$ and ER , when compared to tumors of epithelial origin.
\end{abstract}

Keywords: female dogs, mammary gland tumor, estrogen, progesterone, receptors

\section{INTRODUÇÃO}

Os tumores da glândula mamária de cães têm interesse especial para os pesquisadores que trabalham com neoplasias em razão de algumas similaridades com o câncer de mama humano. Inclusive tem sido proposto, em muitos trabalhos, o estudo dessas lesões na espécie canina como modelo comparativo para a espécie humana (Schneider, 1970; Peleteiro, 1994). As hipóteses etiológicas da neoplasia mamária envolvem a origem viral, influência da dieta e obesidade, componentes genéticos, estresse oxidativo e, principalmente, influência hormonal (Peleteiro, 1994; Fonseca e Daleck, 2000; Zuccari et al., 2001; Silva et al., 2004).

Nas cadelas, a ovariossalpingohisterectomia realizada antes do primeiro estro reduz o risco de desenvolvimento da neoplasia mamária para $0,5 \%$; esse risco aumenta significativamente nas fêmeas esterilizadas após o primeiro ciclo estral $(8,0 \%)$ e o segundo (26\%). A proteção conferida pela castração desaparece após os dois anos e meio de idade, quando nenhum efeito é obtido (Schneider et al., 1970; MacEwen e Withrow, 1996; Zuccari et al., 2001).

Recebido em 8 de maio de 2011

Aceito em 20 de julho de 2012

E-mail: renataramos_vet@yahoo.com.br 
Os estrógenos são considerados os promotores da iniciação das células mamárias cancerígenas e podem aumentar a taxa de proliferação pelo recrutamento de células não cíclicas dentro do ciclo celular. Além disso, alguns protooncogenes nucleares são regulados por transcrição pelos estrógenos, o que sugere uma contribuição direta dos estrógenos na carcinogênese (Schmitt, 1995). Ademais, o estrógeno promove o crescimento celular por estimular a liberação do fator de crescimento tumoral alta (TGF-alfa) e do fator de crescimento semelhante à insulina (IGF-I) e por inibir o fator de crescimento tumoral $\beta$ (TGF- $\beta$ ), além de estimular o crescimento ductal (MacEwen e Withrow, 1996) e aumentar o fator de crescimento endotelial vascular (VEGF), um fator-chave para a angiogênese (Illera et al., 2006).

Em cães, a progesterona exógena estimula a síntese de hormônio do crescimento na glândula mamária com proliferação lóbulo-alveolar e consequente hiperplasia de elementos mioepiteliais e secretórios, induzindo a formação de nódulos benignos em animais jovens ( Mol et al., 1997; Rutteman et al., 2001; Meuten, 2002). Tais alterações, no entanto, podem predispor o tecido a uma transformação maligna (Zuccari et al., 2001). A utilização regular dessas drogas, em fêmeas ou em machos, aumenta em três vezes o risco de aparecimento de carcinomas e tumores benignos (Ferreira e Amorim, 2003).

Receptores de progesterona e estrógeno (PR e ER) estão presentes tanto no tecido neoplásico quanto no tecido normal (Moulton, 1990; Rutteman, 1990; Donnay et al., 1995). Mais de $50 \%$ dos tumores mamários caninos e $65-70 \%$ dos tumores de mama humanos expressam ER e PR (Thuróczy et al., 2007).

Animais com tumores de mama com ER e PR, ou somente ER, apresentam melhor prognóstico que aqueles que possuem somente PR, visto que a presença dos primeiros correlaciona-se com tumores bem diferenciados. A diminuição da relação ER/PR em carcinomas mamários, que originariamente continham esses receptores, tem sido associada com diminuição da diferenciação celular e progressão da doença, tanto em cães quanto em humanos (Sartin et al., 1992).
A função dos receptores hormonais nas neoplasias tem sido exaustivamente estudada. Acredita-se que exista relação entre o número desses receptores e a capacidade proliferativa das células neoplásicas (Costa et al., 2002).

A dependência hormonal dos tumores mamários caninos geralmente diminui com o aumento da malignidade e alta proliferação celular, ocorrendo em tumores malignos com baixa expressão de receptores de progesterona (Geraldes et al., 2000).

Trabalhos que utilizaram técnicas de imunomarcação em tumores de mama de cadelas constataram que $70 \%$ dos tumores benignos e cerca de $40 \%$ a $60 \%$ dos malignos possuem receptores para estrógeno ou progesterona. Desse modo, quanto menos diferenciada a neoplasia, menor a expressão dos receptores hormonais e maior a autonomia das células neoplásicas, tornando pior o prognóstico da cadela (Peleteiro, 1994; Cassali, 2000; Geraldes et al., 2000).

Dentre os adenocarcinomas mamários caninos, 50 a $53 \%$ são ricos em receptores de estrógeno e $44 \%$ são ricos tanto em receptores de estrógeno como de progesterona (Johnston, 1998).

$\mathrm{Na}$ tentativa de estabelecer novos meios de diagnóstico e prognóstico, têm sido desenvolvidos estudos na área da biologia molecular. Tais procedimentos são realizados ao calcular-se o índice de proliferação tumoral e a quantificação do grau de microvascularização dos tumores mamários caninos (Queiroga e Lopes, 2002).

Ao contrário do que ocorre na mulher, a determinação de ER e PR ainda não é utilizada rotineiramente no prognóstico de carcinomas mamários caninos e felinos, e nenhuma terapia endócrina é normalmente dada a esses animais. $\mathrm{O}$ diferente padrão de expressão dos hormônios esteroides nos tumores mamários caninos e felinos pode ser relevante para selecionar as pessoas que podem se beneficiar da terapia endócrina e para estudar protocolos terapêuticos baseados na administração de antagonistas de receptores de hormônios esteroides (Milanta et al., 2005).

O objetivo deste trabalho foi avaliar a expressão gênica dos receptores de estrógeno e 
progesterona, por meio da técnica de q-PCR, de cadelas portadoras de neoplasias mamárias.

\section{MATERIAL E MÉTODOS}

Vinte e seis animais portadores de tumores mamários, 24 malignos e duas lesões benignas, foram submetidos à mastectomia. Fragmentos das amostras foram transferidos para criotubos e armazenados em nitrogênio líquido $\left(-196^{\circ} \mathrm{C}\right)$ para posterior análise. As amostras do grupocontrole $(n=5)$ foram retiradas por meio de biópsia incisional.

O RNA total foi recuperado a partir de 50-100mg de tecido mamário ou neoplásico imerso em $1 \mathrm{~mL}$ de solução Trizol (Invitrogen ${ }^{\circledR}$ ). A cada amostra de tecido, após ser triturada em microtriturador de tecidos (Polytron), foram adicionados $200 \mu \mathrm{L}$ de clorofórmio. Após centrifugação durante 15 minutos a $12000 \mathrm{~g}$ a $4^{\circ} \mathrm{C}$, a fase aquosa foi transferida a um tubo contendo $0,5 \mathrm{~mL}$ de álcool isopropílico e posterior centrifugação durante 10 minutos a $12000 \mathrm{~g}$ a $4^{\circ} \mathrm{C}$. Adicionou-se $1 \mathrm{~mL}$ de etanol $75 \%$ e realizou-se a centrifugação durante cinco minutos a $7500 \mathrm{~g}$ a $4{ }^{\circ} \mathrm{C}$. Após descartar o sobrenadante, o pélete foi dissolvido em água RNase-free e colocado no gelo. Por fim, a amostra foi incubada por 10 minutos a $60^{\circ} \mathrm{C} \mathrm{em}$ banho-maria e armazenada no freezer a $-70^{\circ} \mathrm{C}$.

O RNA total foi solubilizado em água livre de RNase, tratado com DNase I (Invitrogen Life Technologies, Carlsbad, CA, USA). A pureza do RNA foi garantida quando razão da OD 260/280 foi por volta de 2,0. Para cada amostra, cDNA foi sintetizado a partir de $2 \mu \mathrm{g}$ de RNA total, utilizando os componentes do High Capacity cDNA archive kit (Applied Biosystems, Foster City, CA, EUA). As reações de PCR em tempo real subsequentes foram feitas no 7300 RealTime PCR System (Applied Biosystems, Foster City, CA, USA) com condições universais de termociclagem do equipamento: $95^{\circ} \mathrm{C}$ por $10 \mathrm{~min}$, 40 ciclos de $95^{\circ} \mathrm{C}$ por $15 \mathrm{~s}$, e então $60^{\circ} \mathrm{C}$ por $1 \mathrm{~min}$. As reações foram feitas em duplicatas, utilizando $0,4 \mu \mathrm{M}$ de cada primer e $2 \mathrm{X}$ Power SYBR Green PCR master mix (Applied Biosystems, Foster City, CA, USA) em um volume final de $25 \mu \mathrm{L}$. Os primers para os genes alvos analisados foram obtidos através do trabalho desenvolvido por Oliveira (2008), a partir de sequências publicadas no GenBank (www.pubmed.com) e sintetizados pela Invitrogen Life Technologies (Carlsbad, CA, EUA). Curvas de dissociação e eletroforese com gel de agarose foram feitas para confirmar a amplificação apenas da sequência alvo. A expressão gênica foi comparada entre amostras individuais por meio do método do $\Delta \Delta \mathrm{Cq}$ descrito no Applied Biosystems User Bulletin $\mathrm{N}^{\circ}$ 2. O gene gliceraldeido 3-fosfato desidrogenase (GAPDH) foi utilizado como gene de referência para normalização dos resultados (Tab. 1).

A exatidão da quantificação do RNA mensageiro depende da linearidade e eficiência da amplificação da PCR, a qual foi validada e determinada pelo método do $\mathrm{C}_{\mathrm{T}}$ comparativo ou $\Delta \Delta \mathrm{Cq}$ (Wong e Medrano, 2005; Applied Biosystems User Bulletin $\mathrm{N}^{\circ} 2$ ). Foi constituída uma série de seis diluições (10x) a partir do produto de PCR diluído 500 vezes, referente a cada gene, de uma mistura inicial contendo quantidades iguais de cDNA das três amostras de padronização, gerando assim seis pontos de uma curva padrão, para cada um dos conjuntos de primers escolhidos inicialmente para a RT-PCR em tempo real. A linearidade e a eficiência da PCR em tempo real foram deduzidas a partir da inclinação da curva-padrão gerada pelo software 7300 System SDS (Applied Biosystems, Foster City, CA, EUA) para cada um dos genes analisados. A análise de todas as curvas-padrão demonstrou uma alta linearidade $\left(r^{2}=0,99\right)$. A eficiência da PCR $\left(E_{x}\right)$ foi calculada a partir da equação $\mathrm{E}_{\mathrm{x}}=10-1^{-1 / \text { inclinação }}-1$. Uma inclinação de -3,32 implica uma eficiência de reação de $100 \%$. Todos os genes apresentaram valores de inclinação próximos de $-3,32$, e as estimativas de eficiência ficaram entre $99,5 \%$ e $100,5 \%$.

Foi realizada a validação do método $\Delta \Delta \mathrm{Cq}$ para todos os genes, e todos foram validados. Estudou-se a possibilidade de validação do método do $\mathrm{C}_{\mathrm{T}}$ comparativo, de acordo com o User Bulletin $\mathrm{N}^{\circ} 2$ (Applied Biosystems, Foster City, CA, EUA). O método do $\Delta \Delta \mathrm{Cq}$ é simples e fácil para quantificação do RNA mensageiro e se baseia na eficiência de amplificação entre os genes alvo e o fator de normalização (Vandesompele et al., 2002).

Os resultados foram analisados por meio de estatística descritiva. 
Tabela 1. Sequência dos oligonucleotídeos iniciadores utilizados no PCR em tempo real para amplificação dos genes ER $\alpha, E R \beta$, PR e GAPDH

\begin{tabular}{|c|c|c|}
\hline $\begin{array}{c}\text { Nome do } \\
\text { oligonucleotídeo }\end{array}$ & Sequência & Tamanho \\
\hline ER $\alpha$ & S 5'AACGCCTCTGTCTCGTCTGT3' & $110 \mathrm{pb}$ \\
\hline ER $\beta$ & $\begin{array}{l}\text { S 5'TCCCAGCAGTGCCAATAACTCAGA3' } \\
\text { A 5'TGCATACAGAAGTGACGACTGGCA3' }\end{array}$ & $120 \mathrm{pb}$ \\
\hline PR & $\begin{array}{l}\text { S 5'CAAACATGTCAGTGGGCAGATGC3' } \\
\text { A 5'CTGCCACATGGTGAGGCATAATGA3' }\end{array}$ & $110 \mathrm{pb}$ \\
\hline GAPDH & $\begin{array}{l}\text { S 5'GGAGAAAGCTGCCAAATATG3' } \\
\text { A 5'ACCAGGAAATGAGCTTGACA3' }\end{array}$ & $200 \mathrm{pb}$ \\
\hline
\end{tabular}

$\mathrm{S}=$ "sense"; $\mathrm{A}=$ "antisense"; $\mathrm{pb}=$ pares de bases

$\mathrm{ER} \alpha=$ receptores de estrógeno alfa; $\mathrm{ER} \beta=$ receptores de estrógeno beta; $\mathrm{PR}=$ receptores de progesterona; $\mathrm{GAPDH}=$ gliceraldeído 3-fosfato desidrogenase.

\section{RESULTADOS E DISCUSSÃO}

Nas Tabelas 2, 3 e 4, mostram-se os valores mínimos, medianas e máximos das quantificações relativas (QRs) dos receptores de estrógeno alfa $(\mathrm{ER} \alpha)$, de estrógeno beta $(\mathrm{ER} \beta)$ e de progesterona.
Os ER e PR estão presentes tanto no tecido neoplásico quanto no tecido mamário normal (Moulton, 1990; Ruttenman, 1990; Donnay et al., 1993; Donnay et al., 1995). Noventa e cinco por cento do tecido mamário canino normal contém ER e/ou PR (Donnay et al., 1995). Mais de 50\% dos tumores mamários caninos e $65-70 \%$ dos tumores de mama humanos expressam ER e PR (Thuróczy et al., 2007).

Tabela 2. Valores mínimo, mediana e máximo da quantificação relativa $(\mathrm{QR})$ dos receptores de estrógeno alfa (ER $\alpha)$ dos grupos benignos, malignos e controle

\begin{tabular}{cccc}
\hline $\begin{array}{c}\mathrm{ER} \alpha \\
(\mathrm{QR})\end{array}$ & Mínimo & Mediana & Máximo \\
\hline benignos & 0,70 & 181,10 & 361,40 \\
malignos & 0,17 & 7,18 & $1.147,00$ \\
controle & 1,64 & 107,60 & 189,20 \\
\hline
\end{tabular}

Tabela 3. Valores mínimo, mediana e máximo da quantificação relativa (QR) dos receptores de estrógeno beta $(E R \beta)$ dos grupos benignos, malignos e controle

\begin{tabular}{cccc}
\hline ER $\beta$ & Mínimo & Mediana & Máximo \\
\hline benignos & 0,09 & 22,57 & 45,04 \\
malignos & 0,06 & 1,00 & $39.920,00$ \\
controle & 0,89 & 509,90 & $2.000,00$ \\
\hline
\end{tabular}

Tabela 4. Valores mínimo, mediana e máximo da quantificação relativa $(\mathrm{QR})$ dos receptores de progesterona (PR) dos grupos benignos, malignos e controle

\begin{tabular}{cccc}
\hline PR & Mínimo & Mediana & Máximo \\
\hline benignos & 20,23 & 844,20 & $1.668,00$ \\
malignos & 0,40 & 96,50 & $1.612 .000,00$ \\
controle & 13,40 & $10.930,00$ & $26.500,00$ \\
\hline
\end{tabular}


De forma geral, nos tumores malignos, a expressão dos genes que codificam os receptores desses hormônios pode estar diminuída, em particular nas neoplasias de maior grau de malignidade ou nas fases mais avançadas da doença (Peleteiro, 1994). Cerca de $80 \%$ dos tumores e $95 \%$ dos tecidos mamários normais apresentam concentrações detectáveis de ER, PR, ou ambos, e aproximadamente $72 \%$ dos tumores mamários em cadelas apresentam ambos os tipos de receptores, e menos de 20\% apresentam somente um tipo de receptor (Donnay et al., 1995).

Comparando-se as medianas das quantificações relativas dos receptores de progesterona, estrógeno alfa e beta das neoplasias malignas de origem epitelial ou mista (epitelial e mesenquimal), foram observados os seguintes valores constados na Tab. 5 .

Tabela 5. Valores das medianas das quantificações relativas (QRs) dos receptores de progesterona (PR), estrógeno alfa $(\mathrm{ER} \alpha)$ e beta $(\mathrm{ER} \beta)$ das neoplasias malignas de origem epitelial ou mista (epitelial e mesenquimal)

\begin{tabular}{lll} 
& Epitelial $(\mathrm{n}=10)$ & Mista $(\mathrm{n}=14)$ \\
\hline PR & 85,81 & 145,31 \\
ER $\alpha$ & 6,41 & 25,48 \\
ER $\beta$ & 0,40 & 4,88 \\
\hline
\end{tabular}

Segundo Nieto et al. (2000), tumores mamários malignos apresentam uma expressão de ER $\alpha$ menor que os tumores benignos. Segundo Silveira (2009), a imunomarcação de receptores hormonais diminui com a malignidade.

A avaliação dos ER e PR na medicina veterinária é comumente realizada por meio da técnica de imunoistoquímica. Neste trabalho, utilizou-se a técnica de q-PCR e empregou-se a análise de quantificação relativa.

Os resultados obtidos por meio do q-PCR demonstraram que os três grupos de animais, com lesões benignas ou malignas e controle, expressaram receptores de estrógeno alfa, beta e progesterona. Entretanto, devido à disparidade entre os grupos - o grupo das lesões benignas foi representado apenas por dois animais - a comparação entre os grupos não tem validade estatística. Além disso, os valores da quantificação relativa variaram muito entre os animais do mesmo grupo - desvio padrão alto e, por isso, a mediana é considerada o parâmetro que melhor ilustra as diferenças entre os grupos.

Observou-se que a expressão dos receptores neste estudo segue a tendência da expressão descrita em literatura. Ou seja, a glândula mamária normal expressa uma quantidade maior de receptores, seguida das lesões benignas e, por fim, de forma decrescente, dos tumores malignos. Além disso, é importante destacar que todos os tumores malignos expressaram todos os receptores, em maior ou em menor grau. Analisando a expressão dos ER $\alpha$ e ER $\beta$, tanto nos grupos de neoplasias de origem epitelial e mista, a expressão de ER $\alpha$ foi significativamente maior em ambos.

Comparando os dois tipos de receptores, verificou-se que a expressão de ER- $\beta$ foi menor que a dos ER- $\alpha$, na medida em que os ER- $\beta$ foram encontrados em $26 \%$ das neoplasias mamárias malignas, enquanto os outros receptores estavam presentes numa percentagem de tumores compreendida entre $37 \%$ e $70 \%$, em estudos de radioimunoensaio, e entre $10 \%$ e $87,5 \%$, em análises imunoistoquímicas. Essas duas isoformas parecem ter diferentes especificidades de ligação. Os resultados de estudos experimentais indicam que uma das funções dos ER- $\beta$ consiste em modular a atividade transcricional dos ER- $\alpha$ (de las Mulas et al., 2004).

Considerando a classificação histológica dos carcinomas em complexos e simples, verifica-se que os complexos têm maiores concentrações de receptores de estrógenos e progesterona comparativamente aos simples (Thuróczy et al., 2007).

Neste trabalho, a expressão dos PR, ER $\alpha$ e ER $\beta$ foi maior nas neoplasias malignas de origem mista, tumores mistos malignos, em relação às neoplasias malignas epiteliais, carcinomas, confirmando resultados já obtidos. 


\section{CONCLUSÃO}

Os três grupos de animais estudados, com tumor maligno ou benigno e controle, expressam receptores de estrógeno alfa, beta e progesterona. A quantificação relativa mostra uma tendência para expressão maior dos receptores no grupocontrole e menor no grupo de animais com neoplasias malignas. Ocorre expressão maior de $\mathrm{ER} \alpha$ em relação ao ER $\beta$ nas neoplasias, de um modo geral. As neoplasias malignas de origem mista apresentam maiores concentrações dos receptores $\mathrm{PR}, \mathrm{ER} \alpha$ e $\mathrm{ER} \beta$, comparadas às neoplasias de origem epitelial.

\section{REFERÊNCIAS}

CASSALI, G.D. Estudos morfológicos, imunohistoquímicos e citométrico de tumores mamários da cadela - aspectos comparativos com neoplasias da mama humana. 2000. 73f. Tese (Doutorado em Ciência Animal) - Patologia, Escola de Veterinária, Universidade Federal de Minas Gerais, Belo Horizonte.

COSTA, S.D. et al. Factors influencing the prognostic role of oestrogen and progesterone receptor levels in breast cancer. Eur. J. Cancer, v.38, p.1329-1334, 2002.

DE LAS MULAS, J.M.; ORDÁS, J.; MILLÁN, M.Y. et al. Immunohistochemical expression of estrogen receptor $\beta$ in normal and tumoral canine mammary gland. Vet. Pathol., v.41, p.269-272, 2004.

DONNAY, I.; RAUIS, J.; DEVLEESCHOUVER, N. et al. Receptors for oestrogen, progesterone and epidermal growth factor in normal and tumourous canine mammary tissues. J. Reprod. Fertil., v.47, p.501-512, 1993 .

DONNAY, I.; RAUIS, J.; DEVLEESCHOUWER, N. et al. Comparison of estrogen and progesterone receptor expression in normal and tumor mammary tissues from dogs. Am. J. Vet. Res., v.56, p.1188-1194, 1995.

FERREIRA, A.M.R.; AMORIM, F.V. Neoplasia mamária. In: SOUZA, H.J.M. Coletâneas em medicina e cirurgia felina. Rio de Janeiro: L.F. livros de veterinária, 2003. p.327-337.

FONSECA, C.S.; DALECK, C.R. Neoplasias mamárias em cadelas: influência hormonal e efeitos da ovário-histerctomia como terapia adjuvante. Cienc. Rural. v.30, p.731-735, 2000.
GERALDES, M.; GÄRTNER, F.; SCHMITT, F.N. A immunohistochemical study of hormonal receptors and cell proliferation in normal canine mammary glands and spontaneous mammary tumours. Vet. Rec., v.146, p.403-406, 2000.

ILLERA, J.C.; PÉREZ-ALENZA, M.D.; NIETO, A. et al. Steroids and receptors in canine mammary cancer. Steroids, v.71, p.541-548, 2006.

JOHNSTON, S.D. Sistemas Reprodutivos In: SLATER, D. Manual de Cirurgia de Pequenos Animais. 2nd ed. São Paulo: Manole, 1998. v.2, p.2566-2592.

MacEWEN, E.G.; WITHROW, S.J. Tumors of the mammary gland. In: WITHROW, S.J.; MacEWEN, E.G. Small animal clinical oncology. $2^{\text {nd }}$ ed. Philadelphia: Saunders, 1996. p.356-372.

MEUTEN, D.J. Tumors in domestic animals. 4nd ed. Iowa State:Univ. California, 2002. 788p.

MILANTA, F.; CALANDRELLA, M.; BARI, G. et al. Comparison of steroid receptor expression in normal, dysplastic and neoplastic canine and feline mammary tissues. Res. Vet. Sci., v.79, p.225-232, 2005.

MOL, J.A.; SELMAN, P.J.; SPRANG, E.P. et al. The role of progestins, insulin-like growth factor (IGF) and IGF-binding proteins in the normal and neoplastic mammary gland of the bitch: a review. J. Reprod. Fertil., v.51, p.339-344, 1997.

MOULTON, J.E. (Ed.). Tumors in domestic animals. 3nd ed. Berkeley:University of California, 1990. p.672.

NIETO, A.; PEÑA, L.; PÉREZ-ALENZA, M.D. et al. Immunohistologic Detection of Estrogen Receptor Alpha in Canine Mammary Tumors: Clinical and Pathologic Associations and Prognostic Significance. Vet. Pathol., v.37, p.239-247, 2000.

OLIVEIRA, P.C. Avaliação hormonal, imunoistoquímica e da expressão gênica de receptores de estrógeno e progesterona em cadelas (Canis familiaris) nas diferentes fases do ciclo estral e com piometra. 2008. 90f. Tese (Doutorado em Medicina Veterinária - Área de Reprodução Animal). Universidade Estadual Paulista "Júlio de Mesquita Filho" - Unesp, Botucatu.

PELETEIRO, M.C. Tumores mamários na cadela e na gata. Rev. Port. Cienc. Vet., v.89, p.10-28, 1994.

QUEIROGA, F.; LOPES, C. Tumores mamários caninos: pesquisa de novos fatores de prognóstico. Rev. Port. Cienc. Vet., v.47, p.119-127, 2002.

RUTTEMAN, G.R. Hormones and mammary tumor disease in the female dog: an update. In Vivo, v.4, p.33-40, 1990. 
RUTTEMAN, G.R.; WITHROW, S.J.; MACEWEN, E.G. Tumors of the mammary gland. In: WITHROW, S.J.; MACEWEN, E.G. Small animal clinical oncology. 2nd ed. Philadelphia:Sanders, 2001. p.455477.

SARTIN, E.A.; BARNES, S.; KWAPIEN, P. et al. Estrogen and progesterone receptor status of mammary carcinomas and correlation with clinical outcome in dogs. Am. J. Vet. Res., v.38, p.21962200,1992 .

SCHNEIDER, R. Comparison of age, sex, and incidence rates in human and canine breast cancer. Cancer, v.26, p.419-426, 1970.

SCHMITT, F.C. Multistep progression from an oestrogen-dependent growth toward an autonomous growth in breast carcinogenesis. Euro. J. Cancer, v.31, p.2049-2052, 1995.

SILVA, A.E.; SERAKIDES, R.; CASSALI, G.D. Carcinogênese Hormonal e neoplasias hormôniodependentes. Cienc. Rural, v.34, p.625-633, 2004.
SILVEIRA, A.C.T. Caracterização do infiltrado inflamatório e avaliação dos marcadores de prognóstico ki-67, P53, receptor de estrógeno e progesterona no tumor mamário maligno de cadelas. 2009. 113p. Tese (Patologia Veterinária). Faculdade de Ciências Agrárias e Veterinárias do Campus de Jaboticabal - UNESP.

THURÓCZY, J.; REISVAAG, G.J.K.; PERGE, E. et al. Immunohistochemical detection of progesterone and cellular proliferation in canine mammary tumours. J. Comp. Pathol. v.137, p.122-129, 2007.

VANDESOMPELE, J.; DE PRETER, K.; PATTYN, F. et al. Accurate normalization of real-time quantitative RT-PCR data by geometric averaging of multiple internal control genes. Gen. Biol., v.18, p.3, 2002.

WONG, M.L.; MEDRANO, J.F. Real-time PCR for mRNA quantitation. Biotechniques, v.39, p.75-85, 2005.

ZUCCARI, D.A.P.C.; SANTANA, A.E.; ROCHA, N.S. Fisiopatologia da neoplasia mamária em cadelas - revisão. Clin. Vet., n.32, p.50-4, 2001. 